\title{
PENGARUH ALIH FUNGSI LAHAN SAWAH TERHADAP PRODUKSI PADI DI KABUPATEN GOWA PROVINSI SULAWESI-SELATAN
}

\author{
Aminuddin \\ Fakultas Ekonomi Universitas Muslim Indonesia Makassar
}

\begin{abstract}
There are uncertain pattern in the development of rice field function alteration to non-rice field, where the alteration absolutely depends on various factors, such as the development of office building (both public and privat), housing, roadway, etc., in any sub-district at Kabupaten Gowa. The wide of field significantly affects on the total of rice production, but the in the level of $5 \%$, the influence of function alteration of rice field to non-rice field statistically was not significant.
\end{abstract}

Keywords: rice field function alteration and rice production

\section{A. LATAR BELAKANG}

Sulawesi Selatan (Sul-Sel) sampai saat ini masih dikatakan memiliki struktur ekonomi yang agraris, di mana potensi agraris yang ada relatif terbatas. Potensi agraris dapat dilihat melalui persentase perkembangan jumlah penduduk yang bekerja di sektor pertanian, yakni pada tahun 1980 bisa mencapai 50,47 persen, kemudian kembali naik menjadi 52,30 persen tahun 1985, sedangkan di tahun 1995 terjadi penurunan dan mencapai 39,52 persen. (Gowa Dalam Angka, 2006:53).

Petani di daerah Sul-Sel sebagian besar mempunyai kegiatan pokok di sektor pertanian tanaman pangan yaitu: padi-padian, palawija dan hortikultura. Produksi pangan pada kenyataannya merupakan sektor usaha yang utama yang dikelola dengan managemen yang sangat sederhana dan hasil yang diperoleh cukup untuk menjamin pemenuhan kebutuhan sendiri.

Untuk mengatasi keterbatasan areal peruntukan pengembangan tanaman pangan ini, maka upaya yang dilakukan oleh pemerintah adalah dengan meningkatkan mutu intensifikasi pertanian. Cara tersebut bertujuan untuk mempertinggi tingkat produksi total. Intensifikasi di sini adalah berupa penerapan alat produksi yang lebih modern seperti penggunaan traktor sawah pengganti bajak tradisional, penggunaan pupuk, obat-obatan pembasmi hama penyakit, penggunaan bibit varietas unggul dan lain-lain. Dengan dilaksanakan masing-masing cara alternatif tersebut di atas, maka diharapkan produksi total tanaman pangan meningkat.

Terkait dengan perihal di atas tersebut, dapat diketengahkan dua tujuan dari tulisan ini, yaitu menganalisa pengaruh dari luas lahan sawah terhadap produksi total padi selama tahun 2003 dan tahun 2006 di daerah Kabupaten Gowa dan untuk mengetahui pengaruh alih fungsi lahan sawah ke non sawah terhadap produksi total padi di daerah Kabupaten Gowa.

\section{B. KAJIAN TEORITIS}

\section{Teori Produksi Pertanian}

Produksi adalah jumlah hasil. Dalam usaha tani, guna memperoleh hasil produksi petani melakukan usaha pengkombinasian faktor-faktor produksi yang dimiliki seperti; luas tanah, modal seperti pupuk, obat-obatan, bibit dan lain-lain, tenaga kerja, keahlian. 


\section{Journal of Indonesian Applied Economics}

Vol. 3 No. 1 Mei 2009, 1-9

Kemudian produktivitas adalah kemampuan suatu faktor produksi, seperti luas tanah, untuk memperoleh hasil produksi per hektar. Produksi dan produktivitas ditentukan oleh banyak faktor seperti kesuburan tanah, varitas bibit yang ditanam, penggunaan pupuk yang memadai baik jenis maupun dosis, tersedianya air dalam jumlah yang cukup, teknik bercocok tananam yang tepat dan penggunaan alat-alat produksi pertanian yang memadai dan tersedianya tenaga kerja (Partadiredja, 1980: 34).

Dalam kondisi nyata luas dan kesuburan tanah yang dimiliki petani adalah berbeda-beda, demikian pula keadaan lingkungan kehidupan sosial ekonomi mereka. Dengan perbedaan yang ada ini maka usahatani dapat dikelompokkan menjadi:

a. Usahatani yang bersifat subsisten yakni dengan cirri-ciri sebagai berikut:

1.Produksi subsisten (subsistence production) dengan tingkat komersial yang rendah dan produksi digunakan untuk memenuhi kebutuhan keluarga sendiri.

2. Tingkat kehidupan subsisten (subsistence living) yakni yang berhubungan dengan kemampuan memenuhi tingkat kebutuhan hidup yang minimum.

b. Usahatani yang bersifat seperti sebuah perusahaan (farm bussines) dengan ciri-ciri sebagai berikut:

1.Pengalokasian biaya disesuaikan dengan kegiatan usaha yang dilakukan.

2.Pencapaian tingkat efisiensi teknis (penggunaan tenaga kerja dan modal) agar diperoleh kuantitas produksi yang optimum dan pencapaian tingkat efisiensi ekonomis yakni laba yang maksimum (Warton dan Cliffton, 1969: 45).

Walaupun ada perbedaan seperti apa yang diuraikan di atas, dibalik itu ada pula kesamaan diantara petani ini, yakni mereka memandang pertanian sebagai suatu sarana pokok untuk memenuhi kebutuhan keluarga, yaitu melalui hasil-hasil produksi pertanian itu (Mosher, 1969:39).

\section{Kerangka Konsep Dan Hipotesis}

Kabupaten Gowa dalam pembangunan ekonominya, mempunyai sektor unggulan yaitu, pertanian dalam arti luas dan industri kecil dan kerajinan. Sektor pertanian dalam arti luas juga menjadi sektor yang diunggulkan di Kabupaten Gowa, karena sektor ini merupakan sumber pemenuhan kebutuhan pangan masyarakat disamping juga diarahkan untuk menunjang pariwisata. Sedangkan sektor industri kecil dan kerajinan diunggulkan karena disamping untuk menunjang sektor pariwisata, juga dikembangkan untuk kebutuhan ekspor dan juga untuk memenuhi kebutuhan masyarakat. Luas tanah menurut penggunaannya di Kabupaten Gowa dirinci per kecamatan ternyata di daerah Kecamatan Bonto Marannu, Pallangga dan Somba Opu telah terjadi penurunan luas sawah. Sampai dengan tahun 2005 di Gowa penurunan luas sawah dalam adalah yang tertinggi, kemudian disusul oleh Palagga dan terakhir terjadi penurunan luas sawah di Bonto Marannu. Dan secara keseluruhan sampai dengan tahun terakhir tersebut di Kabupaten Gowa telah terjadi alih fungsi lahan sawah ke non sawah.

Dengan memperhatikan peta penurunan luas sawah, dapat diketahui bahwa daerah Kecamatan Somba Opu adalah daerah yang paling tinggi perubahan alih fungsi lahan sawah ke non sawah. Hal ini dimungkinkan mengingat daerah kecamatan ini saat ini telah ditetapkan sebagai daerah pusat pemerintahan Kabupaten. Di Kabupaten Gowa, pembangunan fisik seperti perkantoran pemerintah, jalan raya, perumahan penduduk, pertokoan dan lain-lain, menjadi pendorong terjadinya alih fungsi lahan sawah. Adanya alih fungsi lahan sawah ke non sawah ini maka kemungkinannya akan ber dampak pada sektor pertanian dan juga sektor sosial ekonomi petani. Bila dilihat dari sektor pertanian, maka diperkirakan muncul dari menurunnya luas sawah adalah semakin menurunnya jumlah produksi padi di Kabupaten Gowa.

Dalam penelitian ini khususnya dari produksi padi, maka untuk memperkirakan pengaruh luas sawah yang beralih fungsi ke non sawah terhadap produksi padi, di sini digunakan model regresi log linear bivariabel dan juga model semi log linier multivariable. Kemudian model ini secara statistik dilakukan pengujian, yaitu uji t, uji F, atas koefisien regresi masing-masing dengan tingkat signifikansi sebesar 5\%. Sesuai dengan penjelasan yang diajukan dalam bahasan sebelumnya, 
penelitian ini hanya melihat pengaruh alih fungsi lahan sawah ke non sawah, terhadap produksi padi saja.

Sesuai dengan masalah yang diajukan sebelumnya, maka masalah yang perlu diberikan hipotesis di sini adalah:

1). Bahwa luas sawah berpengaruh positif terhadap produksi padi pada tahun 2003 dan tahun 2006 di daerah Kabupaten Gowa

2). Bahwa alih fungsi diperkirakan berpengaruh positif terhadap produksi padi namun tidak signifikan, mengingat dalam tahun 2003 dan 2006 alih fungsi lahan sawah masih relatif kecil di Kabupaten Gowa

\section{METODE PENELITIAN DAN ANALISIS DATA}

\section{Lokasi Penelitian dan Sumber Data}

Penelitian tentang alih fungsi lahan sawah ke non sawah dilakukan di Kabupaten Gowa. Kabupaten Gowa dipilih karena daerah tergolong daerah pertanian dan mengalami alih fungsi lahan sawah tergolong tinggi diantara daerah kabupaten lain di Sulawesi-Selatan, yakni rata-rata per tahun mencapai 16,06 hektar selama periode tahun 1996-2006. Faktor penyebab dari alih fungsi lahan tersebut adalah pesatnya pembangunan fisik seperti jalan raya, pasar, perumahan, perkantoran, terminal, dan lain-lain. Selanjutnya, data yang dipergunakan dalam penelitian ini adalah data sekunder yang diperoleh dari instansi Bappeda-Kabupaten Gowa.

\section{Identifikasi Variabel}

Variabel yang digunakan dalam analisis data, diidentifikasi sebagai berikut:

1) Luas tanah sawah (hektar/tahun), luas tanah yang digunakan untuk memproduksi padi diukur dalam hektar/tahun.

2) Produksi padi (ton/tahun), adalah jumlah produksi yang mampu dihasilkan, selama satu tahun yang diukur dengan ton/tahun.

3) Luas lahan sawah yang beralih fungsi ke non sawah (hektar/tahun), adalah luas sawah yang dialih fungsikan untuk penggunaan non sawah untuk menghasilkan produksi padi yang diukur dengan hektar/tahun.

\section{Teknik Analisis Data}

Teknik analisis yang digunakan dalam menganalisis data disesuaikan dengan masalah yang diteliti, yakni:

1) Untuk mengestimasi pengaruh dari luas sawah terhadap produksi padi pada tahun 2003 dan tahun 2006, digunakan regresi log linier bivariabel sebagai berikut (Baumann dkk., 1998:60):

$\log Q_{t}=\log a_{0}+a_{1} \log L_{s}+\log E$.

Dengan: $\mathrm{Q}_{\mathrm{t}}=$ produksi padi total (ton). $\mathrm{L}_{\mathrm{s}}=$ Luas lahan sawah tanaman (hektar). $\mathrm{Er}=$ variabel gangguan dalam model (diasumsikan $=0$ ), dan $\mathrm{a}_{0} \ldots \ldots \mathrm{a}_{2}=$ konstanta.

2) Kemudian untuk mengetahui pengaruh luas sawah dan alih fungsi lahan sawah ke non sawah terhadap produksi padi total, digunakan model semi log sebagai berikut:

$\log \mathrm{Q}_{\mathrm{t}}=\log \mathrm{a}_{0}+\mathrm{a}_{1} \log \mathrm{L}_{\mathrm{s}}+\mathrm{a}_{2} \mathrm{D}+\log \mathrm{E}$

Dengan: $\mathrm{Q}_{\mathrm{t}}=$ produksi padi total (ton). $\mathrm{L}_{\mathrm{s}}=$ Luas lahan sawah (hektar). $\mathrm{D}=$ dummy variabel yang dikatagorikan sebagai berikut: $\mathrm{D}=0$ berarti tidak ada alih fungsi lahan sawah ke lahan non sawah. $\mathrm{D}=1$ berarti ada alih fungsi lahan sawah ke lahan non sawah. $\mathrm{Er}=$ variabel gangguan dalam model (diasumsikan $=0$ ), dan $\mathrm{a}_{0} \ldots \ldots \mathrm{a}_{2}=$ konstanta. 
Untuk kelengkapan model analisis ini maka akan dilakukan beberapa uji statistik berkenaan dengan koefisien regresi linier tersebut di atas, yakni uji t statistik, uji F statistik. Kemudian juga dihitung hubungan antara varaibel independent dan variabel dependent dengan menggunakan koefisien korelasi ( $\mathrm{r}$ ) dan koefisien determinasi $\left(\mathrm{R}^{2}\right)$.

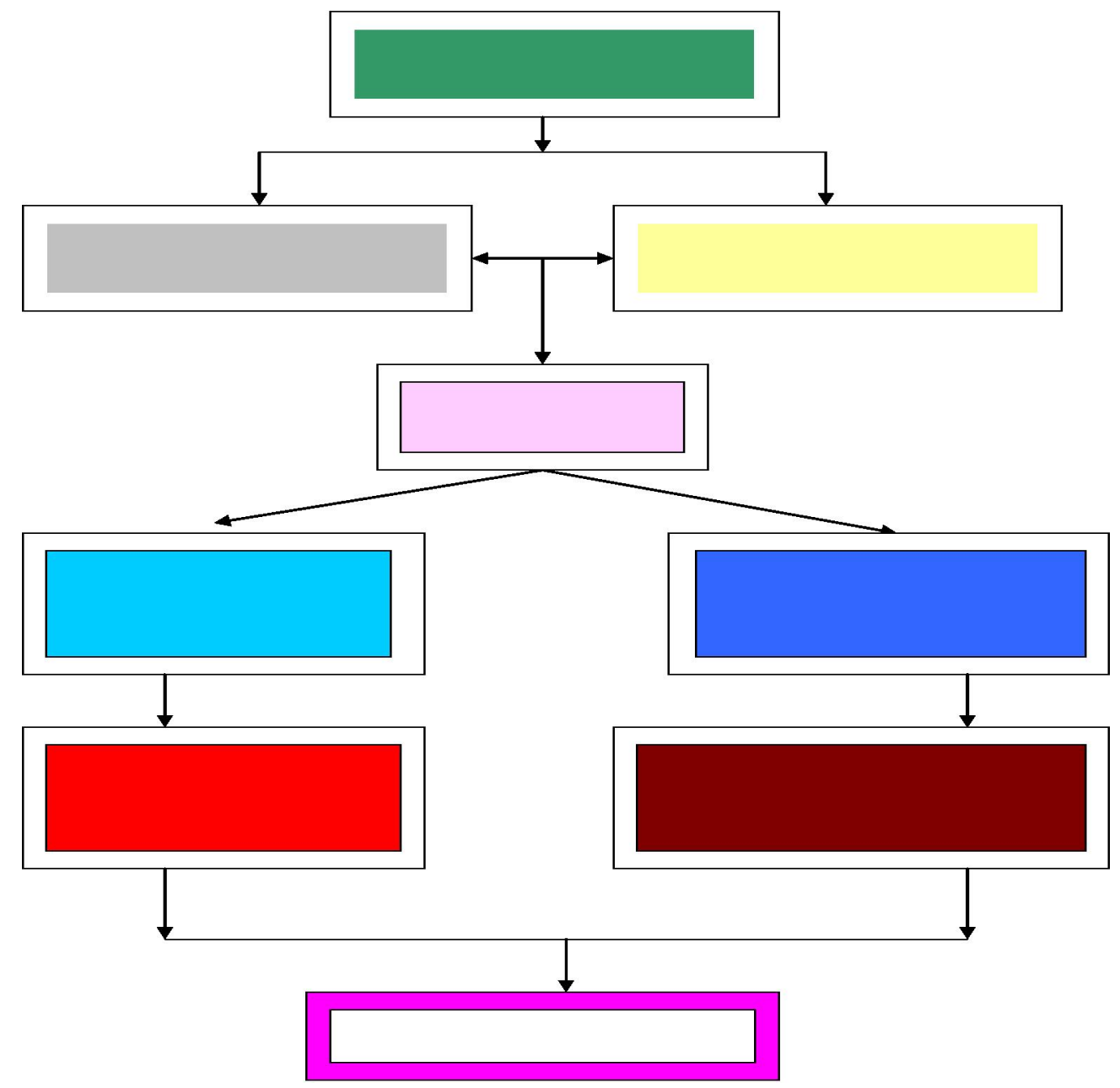

\section{Gambar 1. Kerangka Konsep Penelitian}

\section{HASIL DAN PEMBAHASAN}

\section{Perkiraan Fungsi Produksi Padi Tahun 2003 Di Kabupaten Gowa}

Untuk mengetahui pengaruh luas lahan sawah terhadap produksi total di sini digunakan model regresi $\log \operatorname{linier}$ dengan persamaan : $\log \mathrm{Q}_{\mathrm{t}}=\log \mathrm{a}_{0}+\mathrm{a}_{1} \log \mathrm{L}_{\mathrm{s}}+\log \mathrm{E}$. Dimana: Qt adalah produksi total per kecamatan di Kabupaten Gowa, Ls adalah luas sawah total per kecamatan di daerah Kabupaten Gowa, E adalah variabel kesalahan penafsiran dalam model yang diasumsikan sama dengan nol. $a_{0}$ dan $a_{1}$ adalah koefisien persamaan regresi bivariabel. Dengan menggunakan data luas sawah dan produksi total padi selanjutnya dapat diestimasi fungsi produksi tersebut di atas seperti yang ditunjukkan melalui hasil perhitungan yang disajikan dalam Tabel 1. 
Tabel 1. Hasil Estimasi Persamaan Regresi Bivariabel Tanaman Padi Per Kecamatan Di Kabupaten Gowa Tahun 2003

\section{Coefficients ${ }^{\mathrm{a}}$}

\begin{tabular}{|c|c|c|c|c|c|c|}
\hline \multirow[b]{2}{*}{ Model } & & \multicolumn{2}{|c|}{$\begin{array}{l}\text { Unstandardized } \\
\text { Coefficients }\end{array}$} & \multirow[t]{2}{*}{$\begin{array}{c}\text { Standardi } \\
\text { zed } \\
\text { Coefficien } \\
\text { ts }\end{array}$} & \multirow[b]{2}{*}{$\mathrm{t}$} & \multirow[b]{2}{*}{ Sig. } \\
\hline & & B & Std. Error & & & \\
\hline 1 & (Constant) & .537 & .143 & & 3.753 & .033 \\
\hline & LOG.LS.3 & 1.156 & .046 & .998 & 24.943 & .000 \\
\hline
\end{tabular}

a. Dependent Variable: LOG.PRD

Data hasil analisis dalam Tabel 1 di atas disusun dalam bentuk persamaan akan nampak sebagai berikut:

$$
\begin{aligned}
& \log \mathrm{Qt}=\log 0.537+1,156 \log \mathrm{Ls} \\
& (\mathrm{t}=3,753) \quad(\mathrm{t}=24,943) \\
& \mathrm{R}^{2}=0,995 \quad \mathrm{r}=0,998 \quad \mathrm{~F}=622,133
\end{aligned}
$$

Hasil estimasi koefisien regresi fungsi produksi padi tahun 2003 di atas dapat diartikan:

(1) $a_{1}=1,156$ ini artinya bahwa luas sawah tanaman padi berpengaruh positif terhadap produksi total padi di setiap daerah kecamatan di Kabupaten Gowa, yakni jika terjadi peningkatan luas sawah sebesar 1 hektar maka akan mampu meningkatkan jumlah produksi padi sebanyak 12,914 ton selama setahun. Dan kesimpulan tersebut adalah signifikan karena secara statistik didukung dengan hasil uji, $t$, statistik dengan tingkat signifikansi pengujian sebesar $\alpha=5 \%$.

(2) $\mathrm{R}^{2}$ adalah sebesar 0,995 ini artinya bahwa 95,5 persen variasi perubahan dari variabel independent (variabel luas sawah) menentukan naik turunnya perubahan variabel dependent (variabel produksi total tanaman padi) di setiap kecamatan di Kabupaten Gowa dan sisanya 4,5 persen ditentukan faktor diluar model.

(3) $\mathrm{r}$ adalah 0,998 ini artinya bahwa ada hubungan yang sangat positif dan tergolong sangat kuat antara variabel independent ( luas sawah) dengan variabel dependent ( produksi total tanaman padi) di setiap kecamatan di Kabupaten Gowa.

\section{Perkiraan Fungsi Produksi Padi Tahun 2005 Di Kabupaten Gowa}

Dengan menggunakan data luas sawah dan produksi total padi selanjutnya dapat diestimasi fungsi produksi padi total, seperti yang ditunjukkan melalui hasil perhitungan yang disajikan dalam Tabel 2. Selanjutnya data hasil analisis dalam Tabel 2 di atas dapat digunakan untuk menyusun fungsi produksi padi total, sebagai berikut:

$$
\begin{array}{ccc}
\log \mathrm{Qt}= & \log 0.524+ & 1,149 \log \mathrm{Ls} \\
& (\mathrm{t}=1,394) & (\mathrm{t}=9,568) \\
\mathrm{R}^{2}=0,984 & \mathrm{r}=0,968 & \mathrm{~F}=91,544
\end{array}
$$


Tabel 2.Hasil Estimasi Persamaan Regresi Bivariabel Tanaman Padi Per Kecamatan Di Kabupaten Gowa Tahun 2006

\section{Coefficients}

\begin{tabular}{|c|c|c|c|c|c|c|}
\hline \multirow{2}{*}{\multicolumn{2}{|c|}{ Model }} & \multicolumn{2}{|c|}{$\begin{array}{c}\text { Unstandardized } \\
\text { Coefficients }\end{array}$} & \multirow{2}{*}{$\begin{array}{c}\text { Standardi } \\
\text { zed } \\
\text { Coefficien } \\
\text { ts } \\
\text { Beta } \\
\end{array}$} & \multirow[b]{2}{*}{$\mathrm{t}$} & \multirow[b]{2}{*}{ Sig. } \\
\hline & & $B$ & Std. Error & & & \\
\hline & (Constant) & .524 & .376 & & 1.394 & .258 \\
\hline & LOG.LS5 & 1.149 & .120 & .984 & 9.568 & .002 \\
\hline
\end{tabular}

a. Dependent Variable: LOG.PRD5

Hasil estimasi koefisien regresi fungsi produksi padi tahun 2005 di atas dapat diartikan:

(1) $\mathrm{a}_{1}=1,149$ ini artinya bahwa luas sawah tanaman padi berpengaruh positif terhadap produksi total padi di setiap daerah kecamatan di Kabupaten Gowa, yakni jika terjadi peningkatan luas sawah sebesar 1 hektar maka akan mampu meningkatkan jumlah produksi padi sebanyak 1,149 ton selama setahun. Dan kesimpulan tersebut adalah signifikan karena secara statistik didukung dengan hasil uji, $\mathrm{t}$, statistik dengan tingkat signifikansi pengujian sebesar $\alpha=5 \%$.

(2) $\mathrm{R}^{2}$ adalah sebesar 0,984 ini artinya bahwa 98,4 persen variasi perubahan dari variabel independent (luas sawah) menentukan naik turunnya perubahan variabel dependent (produksi total tanaman padi) di setiap kecamatan di Kabupaten Gowa dan sisanya 1,6 persen ditentukan faktor di luar model.

(3) $\mathrm{r}$ adalah 0,968 ini artinya bahwa ada hubungan yang sangat positif dan tergolong sangat kuat antara variabel independent (luas sawah) dengan variabel dependent (produksi total tanaman padi) di setiap kecamatan di Kabupaten Gowa.

\section{Pengaruh Alih Fungsi Lahan Sawah ke Non Sawah Terhadap Produksi Padi Total Di Kabupaten} Gowa

Untuk mengetahui pengaruh alih fungsi luas lahan sawah ke non sawah terhadap produksi padi total di sini digunakan model regresi semi log linier multivariable dengan persamaan : Log $\mathrm{Q}_{\mathrm{t}}=\log \mathrm{a}_{0}+\mathrm{a}_{1} \log \mathrm{L}_{\mathrm{s}}+\mathrm{a}_{2} \mathrm{D}+\log$ E. Dimana $\mathrm{Qt}$ adalah produksi total per kecamatan di Kabupaten Gowa. Ls adalah luas sawah total per kecamatan di daerah Kabupaten Gowa. D adalah varaibel dummy dengan katagori: $\mathrm{D}=1$ berarti ada sawah yang ber alih fungsi ke non sawah. $\mathrm{D}=$ 0 berarti tidak ada luas sawah yang beralih fungsi ke non sawah. E adalah variabel kesalahan penafsiran dalam model yang diasumsikan sama dengan nol. $\mathrm{a}_{0}, \mathrm{a}_{1} \mathrm{a}_{2}$ adalah koefisien persamaan regresi semi log multivariabel.

Dengan menggunakan data luas sawah dan produksi total padi selanjutnya dapat diestimasi fungsi produksi padi total, seperti yang ditunjukkan melalui hasil perhitungan data yang disajikan dalam Tabel 3 Data hasil analisis dalam Tabel 3 disusun dalam bentuk persamaan akan nampak sebagai berikut:

$$
\begin{gathered}
\log \mathrm{Qt}=\begin{array}{c}
0.833+ \\
(\mathrm{t}=9,996)
\end{array} \begin{array}{c}
(\mathrm{t}=30,023) \\
\mathrm{R}^{2}=0,999 \quad \mathrm{r}=1,00 \quad \mathrm{~F}=1165,050
\end{array}
\end{gathered}
$$

Hasil estimasi koefisien regresi fungsi produksi padi tahun 2003 di atas dapat diartikan:

(1) $a_{1}=0,968$ ini artinya bahwa luas sawah tanaman padi berpengaruh positif terhadap produksi total padi di setiap daerah kecamatan di Kabupaten Gowa, yakni jika terjadi peningkatan luas sawah sebesar 1 hektar maka akan mampu meningkatkan jumlah produksi padi sebanyak 
0,968 ton selama setahun. Dan kesimpulan tersebut adalah signifikan karena secara statistik didukung dengan hasil uji, $t$, statistik dengan tingkat signifikansi pengujian sebesar $\alpha=5 \%$.

(2) $a_{2}=0,403$ ini artinya bahwa jika terjadi alih fungsi sebesar 1 persen maka produksi padi total masih mampu meningkat sebesar 0,403 persen pertahun di daerah kecamatan di Kabupaten Gowa. Hasil estimai ini didukung hasil uji ,t, statistik yang signifikan pada tingkat signifikansi $\alpha$ $=5 \%$. Dan ini berarti pula bahwa sampai tahu 2005 walaupun terjadi banyak alih fungsi lahan sawah ke non sawah nampaknya belum nyata dapat dibuktikan terjadinya penurunan produksi padi total di daerah kecamatan di Kabupaten Gowa tahun 2005.

(3) $\mathrm{R}^{2}$ adalah sebesar 0,999 ini artinya bahwa 99,9 persen variasi perubahan dari variabel independent (luas sawah) menentukan naik turunnya perubahan variabel dependent (produksi total tanaman padi) di setiap kecamatan di Kabupaten Gowa dan sisanya 0,1 persen ditentukan faktor diluar model.

(4) $\mathrm{r}$ adalah 1,000 ini artinya bahwa ada hubungan positif dan sempurna dan tergolong sangat kuat antara variabel independent (luas sawah) dengan variabel dependent (produksi total tanaman padi) di setiap kecamatan di Kabupaten Gowa.

Tabel 3. Hasil Estimasi Persamaan Regresi Multivariabel Semi Logarithma Tanaman Padi Per Kecamatan Di Kabunaten Gowa Tahun 2003

Coefficients $^{\mathrm{a}}$

\begin{tabular}{|c|c|c|c|c|c|c|}
\hline \multirow[b]{2}{*}{ Model } & & \multicolumn{2}{|c|}{$\begin{array}{l}\text { Unstandardized } \\
\text { Coefficients }\end{array}$} & \multirow{2}{*}{$\begin{array}{c}\text { Standardi } \\
\text { zed } \\
\text { Coefficien } \\
\text { ts }\end{array}$} & \multirow[b]{2}{*}{$\mathrm{t}$} & \multirow[b]{2}{*}{ Sig. } \\
\hline & & $B$ & Std. Error & & & \\
\hline \multirow[t]{3}{*}{1} & (Constant) & .833 & .084 & & 9.922 & .010 \\
\hline & LOG.LS5 & .968 & .032 & .829 & 30.023 & .001 \\
\hline & DUMMY & .403 & .047 & .234 & 8.485 & .014 \\
\hline
\end{tabular}

a. Dependent Variable: LOG.PRD5

\section{E. KESIMPULAN DAN REKOMENDASI}

\section{Kesimpulan}

Berdasarkan hasil bahasan bab sebelumnya dapat dikemukakan simpulan berikut:

1) Bahwa pola perkembangan alih fungsi lahan sawah tanaman pangan ke non sawah polanya tidak tentu, artinya alih fungsi lahan sawah sangat tergantung oleh banyak faktor seperti terjadinya pembangunan fisik seperti perkantoran (pemerintah, swasta) perumahan penduduk, jalan raya dan lain-lain, di suatu wilayah kecamatan di Kabupaten Gowa.

2) Bahwa luas lahan sawah nyata berpengaruh meningkatkan produksi total tanaman padi, sedangkan luas sawah yang beralih fungsi ke non sawah belum dapat membuktikan berpengaruh menurunkan produksi padi total di Kabupaten Gowa, yang mana hasil kesimpulan tersebut di atas didukung berdasarkan hasil uji statistik pada tingkat signifikansi $5 \%$.

3) Bahwa luas lahan sawah nyata berpengaruh meningkatkan produksi tanaman pangan total, sedangkan luas sawah yang beralih fungsi ke non sawah belum dapat membuktikan berpengaruh menurunkan produksi tanaman pangan total di Kabupaten Gowa, yang mana hasil ini didukung berdasarkan hasil uji secara statistik yang signifikan pada tingkat signifikansi $5 \%$. 


\section{Journal of Indonesian Applied Economics}

Vol. 3 No. 1 Mei 2009, 1-9

\section{Rekomendasi}

Dengan hasil kesimpulan di atas maka dapat diberikan saran guna menyempurnaan hasil penelitian ini, yakni:

1) Untuk menjaga agar produksi tanaman padi dan juga tanaman pangan tidak mengalami penurunan dimasa mendatang maka perlu upaya untuk mempertahankan luas lahan sawah di Kabupaten Gowa seperti keadaan sekarang ini, karena walaupun belum ada bukti empirik yang menyatakan bahwa banyaknya alih fungsi lahan sawah ke non sawah akan menurunkan produksi total komoditi tersebut di atas, namun secara logika jika luas tanaman komoditi tersebut terus menerus mengalami penurunan di masa mendatang dapat diduga akan menyebabkan penurunan dalam penyedaiaan bahan pangan ke depannya.

2) Penelitian yang dilakukan kali ini menggunakan data yang amat terbatas yakni dalam dua tahun yang berbeda yaitu tahun 2003 dan tahun 2005, maka agar hasil penelitiannya lebih baik perlu diupayakan penggunaan data dengan periode tahun yang lebih lama.

\section{DAFTAR PUSTAKA}

(2003). Bank Indonesia, Kajian Perkembangan Ekonomi dan Keuangan Provinsi Sulawesi Selatan. Triwulan II, Gowa.

(2003). Biro Pusat Statistik: Gowa Dalam Angka, Bappeda-Kabupaten Gowa, BPS Kabupaten Gowa. Gowa.

(2007). Pemerintah Daerah Kabupaten Gowa. Gowa Selayang Pandang. Pemda Kabupaten Gowa, Gowa.

(2005). Laporan Penelitian: Peluang Pasar Komoditas Pertanian Tanaman Pangan dan Hortikultura di Provinsi Sulawesi-selatan, Dinas Pertanian Tanaman Pangan Provinsi Sulawesi Selatan.

(2006). Biro Pusat Statistik Propinsi Sulawesi Selatan: Gowa Dalam Angka.

(1985). Kantor Statistik Provinsi Sulawesi Selatan: Buku Saku Statistik Gowai.

Susenas. (1997). Dalam Mubyarto, Pengantar Ekonomi Pertanian, Penerbit, LP3ES, Cetakan ke tiga, Jakarta.

Ace Partadiredja. (1980). Beberapa Masalah Dalam Produksi Bahan Makanan, Prisma LP3ES, (September), Jakarta.

Achmad Soeharjo. (1987). Thesis. Institut Pertanian Bogor, Bogor.

Arifin, A. (1977). Faktor-Faktor Yang Mempengaruhi Produksi Beras di Kabupaten Daerah Tingkat II Ketapang Kalimantan Barat. Tesis. Program Pasca Sarjana UGM (Tidak Dipublikasikan), Yogyakarta.

Binns, B.O. (1950). The Consolidation of Fragmented Agricultural Holdings, FAO Agricultural Stdies, No 11, Rome, Dalam Mubyarto: Pengantar Ekonomi Pertanian, Penerbit, LP3Es, Cetakan ke tiga, Jakarta.

Consuelo G.Sevilla, Iesus A.Ochave, Twilla G. Punsalan, Bella P.Regala, Gabriel G. Uriarte. (1993). Pengantar Metode Penelitian. Terjemahan Alimuddin Tuwu, UI. Jakarta.

Duane D. Baumann, Dkk. (1998). Urban Water Demand Management and Planning. McGraw Hill Inc., New York. 
Endah Murniningtyas. (2006). Strategi Pengendalian Alih Fungsi Lahan Pertanian. Direktorat Pangan Dan Pertanian Kementerian Perencanaan Pembangunan Nasional.

Irawan. (2006). Multi Fungsi Lahan dan Revitalisasi Pertanian, Balai Penelitian Tanah, Balai Besar Litbang Sumber Daya Pertanian, dalam: Surat Kabar Pembaharuan.

Klim, S. (1958). The Pattern of Land Tenure Reform in East Asia After World War II, Dalam Mubyarto: Pengantar Ekonomi Pertanian, Penerbit, LP3Es, Cetakan ke Tiga, Jakarta.

Lyli Fauzia. (2004). Pengaruh Alih Fungsi Lahan Pertanian Terhadap Sosial ekonomi Masyarakat, (Studi Kasus Di Kecamatan Tanjung Moara Kabupaten Deli Serdang, Program Pascasarjana Universitas Sumatra Utara.

Memberita Ginting. (2005). Faktor-Faktor yang Mempengaruhi Alih Fungsi Lahan Sawah Terhadap Pendapatan Petani: Studi Kasus Di Desa Munte Kabupaten Karo, Program Pascasarjana Universitas Sumatra Utara - Medan.

Mosher, A.T. (1969). Subsistence Agriculture and Economics Development, dalam Tesis: I K Djayastra: Respons Petani Sayur Terhadap Perubahan Harga Di Bali, Yogyakarta.

Mubyarto (1997). Pengantar Ekonomi Pertanian, LP3ES, Cetakan ke Tiga, Jakarta.

Muhammad Iqbal dan Sumariyanto. (2007). Strategi Pengendalian Alih Fungsi Lahan Pertanian Bertumpu Pada Partisipasi Masyarakat. Pusat Analisis Sosial Ekonomi Dan Kebijakan Pertanian, Bogor.

Soekartawi. (2003). Teori Ekonomi Produksi, Pokok Bahasan Fungsi Produksi Cobb Douglas, Raja Grafindo Persada, Jakarta.

Suarta, Dewa Nyoman. (2003). Analisis Produksi Pada Usahatani Dengan Program Peningkatan Mutu Intensifikasi (PMI) Padi di Kabupaten Tabanan, Tesis, Program Pasca Sarjana Universitas Udayana (Tidak Dipublikasikan). Denpasar.

Sugiarto. (1995). Strategi dan Operasional Pembangunan Pertanian Menjelang Perdagangan Global, Pusat Peneliti Sosial Ekonomi Pertanian, Bogor.

Warner Roll. (1983). Struktur Pemilikan Tanah di Indonesia, Penerbit CV. Rajawali Cetakan Pertama, Jakarta.

Warton. Jr dan Cliffton R,. (1969). Subsistence Agriculture and Economics Development, Aldine Publishing Company, Chicago. 